\title{
A instabilidade da díade XY: circuitando o dimorfismo sexual normativo
}

\author{
El descubrimiento de los \\ cromosomas sexuales. Un hito en \\ la historia de la Biología.
}

DELGADO ECHEVERRÍA, Isa bel.

Madrid: Consejo de Investigaciones Científicas, 2007. 734 p.

Isabel Delgado Echeverría nasceu em Zaragoza em 1960. É licenciada em Ciências Biológicas pela Universidade Complutense de Madrid. Trabalha desde 1985 como professora de Biologia e Geologia no ensino secundário. Sua tese intitulada Las investigaciones sobre la determinación del sexo y la diferencia sexual (1891-1985) Ihe deu o título de doutora em Medicina, na Universidade de Zaragoza. Ela pertence ao grupo Genciana (investigações em gênero e ciência) do SIEM (Seminário Interdisciplinar de Estudos da Mulher) da mesma universidade. Em 1999 recebeu o prêmio de investigação feminista "Concepción Gimeno de Flaquer", e em 2003 o prêmio "Dynamis de Fomento de al Investigación en Historia de la Medicina e de la Salud".

Seu livro El descubrimiento de los cromosomas sexuales. Un hito en la historia de la Biología, public ado pelo Consejo de Investigaciones Científicas em Madrid, no a no de 2007, com 734 páginas, a nalisa os trabalhos científic os publicizados entre 1870 e 1940 em relação a os problemas biológicos da determinação do sexo. Naquela época, as preocupações giravam em tomo de diferentes perspectivas, que são fundamentalmente três: ambientalista (na qual o sexo dependeria das condições ambientais e nutriciona is em que o embrião se desenvolveria), morfológica (existiriam partículas nas células que determinariam o sexo), e fisiológica (seria o metabolismo celular no ovo o que produziria um ou outro sexo). A autora mostra como o descobrimento dos cromossomos sexua is em 1905 fez com que as teorias morfológicas se impusessem sobre as demais, a o mesmo tempo que o estudo da herança relacionada com os cromossomos sexua is foi o ponto de partida da genética cromossômica que Morgan e seus colaboradores desenvolveram a partir de 1910 , considerada a segunda revolução genética, se tomada a de Mendel como a primeira.

o tema do dimorfismo sexual normativo constitui o eixo da preocupação central do livro, embora existam outros focos que tomam esse material fascinante. 0 seu apanhado histórico seria já em si uma grande contribuição para os estudos sobre a história da ciência, se considerada a forma como a autora trabalha com a riqueza documental e como elabora o seu método de coleta, armazenamento, organização e interpretação dos dados. Mas sua riqueza se amplia muito, a o considerar-se a original contribuição que ela oferece para os estudos de gênero e ciência. A primeira razão a demarcar é o fato de que a autora inclui nesse seu trabalho a trajetória de várias mulheres pesquisadoras, como Nettie Maria Stevens. Além disso, é de extrema relevância e muito instrutivo o modo como põe em destaque os traços do and rocentrismo, presente nos discursos da maior parte dos trabalhos a nalisados.

A posição dessa literatura crítica, embora com a particularidade de estar nas ciências chamadas naturais, se aproxima de outras existentes no campo da determinação sexual, como é o caso de Nelly Oudshoom, ${ }^{1}$ em suas análises sobre os contextos do desenvolvimento dos estudos sobre hormônios, o caso 
de Cyntia Kraus, ${ }^{2}$ em seus estudos sobre a determinação do sexo, o caso de Tamanini, ${ }^{3}$ em seu capítulo de livro sobre a sexagem de embriões, e de llana Lowy e Delphine Gardey, ${ }^{4}$ em seu livro sobre a invenção do natural, entre outros textos importantes no campo da ciência e gênero.

Seguindo o caminho do texto, verifica-se como a autora apresenta um estudo particular da história da biologia e do contexto do descobrimento dos cromossomos sexua is, o que permite perceber, mais uma vez, o que os estudos de gênero têm insistentemente demonstrado: que as diferenças entre os sexos de homens e mulheres são estabelecidas não por leis naturais biológicas, e que as diferenças biológicas não são a origem das diferenças sociais entre homens e mulheres e nem o fundamento dos diferentes papéis que se esta belecem para os indivíduos humanos de um e de outro sexo.

Perseguindo argumentos críticos, polêmicas e lutas entre diferentes campos do conhecimento, a autora produz uma teia muito bem articulada por uma rede de informações colhidas de documentos históricos, da bibliografia dos autores e das instituições, e constrói assim uma produção de sentido que dá clareza e lógica a uma nova leitura sobre as teorias em suas várias dimensões, mas em especial thes é fiel, visibilizando-as para que interajam com quem as lê.

Assim, encontra-se no seu primeiro capítulo a descrição e apresentação analític a da tradição herdada a té o século XIX, a partir do mundo antigo e medieval, e os principais pressupostos do mundo moderno. A autora demonstra uma série de estudos com contradições teóricas, experimentações ambíguas e a té discordantes demarcadoras do conhecimento biológico sobre os sexos. Demonstra como padrões socia is influencia ram a produção do conhecimento; como variantes na organização sexual e no comportamento de machos e fêmeas são tratadas como exceções a uma norma que não se especifica; como as explicações são prolíferas se a espécie em questão a ltera formas de reprodução a ssexual com indivíduos sexuados, e os contrapõem às espécies em que machos são maiores do que as fêmeas; e como as teorias silenciam quando machos e fêmeas copulam e dão lugar a ovos fecundados.

A autora persegue ao longo dos capítulos uma resposta à pergunta sobre como foram construídos conceitos que se chocam com uma boa parte das formas de vida que se está descrevendo. Para isso, faz um rastreamento sistemático dos últimos anos da história da biologia, origem das idéias atuais sobre a determinação do sexo, bem como das chaves de sua simplific ação no processo de transmissão e divulgação. Segue a trilha dos descobrimentos dos cromossomos sexuais, para assinalar um tempo e lugar e para estabelecer comparações. Centra-se nas últimas décadas do século $\mathrm{XIX}$, considerando que os cromossomos sexua is foram descritos pela primeira vez em 1905 e nas primeiras décadas do século XX.

Ao longo de um texto denso e enciclopédico, percorre o caminho sob a mira de três objetivos: no primeiro, averigua o que estimulou a curiosidade necessária para se chegara observara o mic roscópio cromossomos concretos, e como se chegou a constatar que esses cromossomos eram diferentes entre fêmeas e machos. Mesmo assim acontecendo, investiga como conviveram em um mesmo período histórico os descobrimentos sobre os variados modos de reprodução e os diferentes sistemas de determinação sexual. Como parte do mesmo objetivo, propõe-se a determinar onde e como foram realizados e quem realizou esses desc obrimentos e que meios os difundiram.

Seu segundo objetivo é colocar em manifesto que os diversos conceitos, termos e explic ações da biologia atual que transmitem a idéia da primazia masculina têm sua origem em concepções defendidas em séculos anteriores, assim como se esforça para dissociar o que foi resultado do trabalho científico do que é a projeção dos preconceitos socia is. Seu terceiro objetivo de interesse para as gerações atuais e futuras é o de constatar a existência de autoria feminina nos descobrimentos biológicos do passado. Nesse ponto, apresenta dados de como a comunidade científic a não foi justa com as mulheres, quanto à concessão de prêmios e honras ou de como o registro dos seus descobrimentos ficou oculto, à sombra dos seus maridos e colaboradores. A motivação para este último objetivo advém do fato de que uma das descrições de cromossomos sexua is publicada em 1905 havia sido realizada por mulheres.

Para perseguir seus objetivos, a autora apresenta, nos capítulos 1, 2 e 3, uma revisão baseada na literatura histórica em que contextualiza as idéias e teorias referentes à determinação do sexo registra das na história da ciência ocidental. Busca as raízes, conceitos e preconceitos repassando a filosofia grega e 
detalha o século XIX, quando se produziram o nascimento e o desenvolvimento da biologia modema. Analisa as conseqüências da teoria mendeliana da hereditariedade em relação com uma possibilidade de determinação genética do sexo e confluência de distintas vias de análise do problema a partir do a no de 1900.

No capítulo 4, detalha sua estratégia de busca e de análise bibliográfica que a levaram a recompilar 263 artigos científicos. Ela os contrasta com a literatura histórica e os a nalisa a partir das suas diferentes disposições teóric as metodológicas, no que se refere às perspectivas morfológica, ambientalista e fisiológica. Desenvolve esse capítulo, que denomina como o contexto do descobrimento, a partir de investigações e teorias sobre a fecundação, o problema dos diferentes modos de reprodução e a herança na determinação do sexo. É um c apítulo apaixonante, com a presentação detalhada dos autores do contexto das teorias da fecundação, dos diferentes modos de reprodução, da transmissão hereditária na reprodução e da determinação do sexo. Localiza-se nele o desenvolvimento do microscópio óptico e um enorme desenvolvimento técnico que permitiu a descrição dos gametas e gônadas da maior parte dos grupos de organismos.

Para as questões de gênero, é muito interessante o modo como a autora constrói a teia de sua rede e mostra o descobrimento de óvulos e espermatozóides em todos os grupos a nima is, vertebrados e invertebrados, e em seus a nálogos, as plantas. Demonstra como a descrição dos processos de fusão de gametas na fecundação conduziu, a o final da década de 1850, a um paradigma único sobre a reprodução sexual no qual se unificavam os reinos animal e vegetal, mesmo se, nas considerações teóricas escritas por diferentes investigadores, pudessem ser encontrados pontos de vista mais ou menos mecanicistas, morfológicos, fisiológicos e matizados com diferentes graus de adesão ou crítica às teorias da preformação ou epigêneses.

No capítulo 5, a autora ocupa-se do tema da partogêneses, analisando documentos origina is a partirde varia das fontes de informação primária e secundária: bibliografias de manuais de história, biologia, medicina e ciência, manua is universitários de diferentes disciplinas, bibliografias de trabalhos monográficos, teses de doutorado e licenciatura, catálogos de diversas bibliotecas. Utiliza-se de redes de informações a partir de documentos recupera- dos de publicações anteriores. Segundo ela mesma, a busca exaustiva inicial, que incluía os séculos XIX e XX, lhe permitiu recompilar ma is de duas mil referências bibliográficas, cujo período de publicação abarca de 1836 a 1985.

Sua a nálise centra-se nos artigos porque estão mais próximos do processo de descobrimento. Nesse aspecto, é possível encontrar meticulosa a nálise bibliométrica, sendo referida a quantidade, autores, países, números e cidade das publicações. Há a inda gráficos sobre a distribuição cronológica das referências bibliográfic as, o que permite loca lizar como certos temas se concentram em determinados períodos históricos, com a predominância de certosidiomas de seus países correspondentes. Essa metodologia bibliométrica dá uma noção geral da litera tura encontra da e ensina sobre uma metodologia nem sempre tão comum entre nós. Ao compor os desenhos, não está apenas em consonância com outros períodos históricos, mas também demonstra um esforço investigativo revelador de temas novos e do problema da determinação do sexo entre as décadas de 1880 e 1930 que é original.

Nos capítulos 6, 7 e 8, a autora se ocupa da questão da partenogêneses a partir dos conhecimentos estabelecidos pelas investigações oc orridas entre 1878 e 1912 e que colocavam em questão a necessidade da a tuação do espermatozóide. Pacientemente, esc rutina as diferentes polêmicas geradas pela partenogêneses. Desenvolve a análise sobre a perspectiva morfológica nessas discussões, seguida das perspectivas ambientalista e filosófica que são focadas nos capítulos 8 e 9 . Isabel Delgado Echeverria trabalha de modo organizado as muitas informações e a magnitude da sua originalidade.

Depreendem-se do seu texto várias possibilidades analíticas, não apenas para aumentar a valoração de cada aporte na determinação do sexo, mas também para fazer ver a situação desses a portes em relação a os centros de interesse, às relações de força entre instituições e países, assim como os principa is temas de debates, a evolução das idéias sobre a determinação do sexo, o desenvolvimento das ciências morfológicas e as considerações a mbienta is. 0 texto ta mbém aborda as inúmeras disc ussões esta belec idas entre os embriolog istas e fisiólogos que adotaram um ponto de vista holístico e descartaram a influência dos fatores a mbientais com a adoção de uma perspectiva "intemalista" sobre a base de que o sexo estaria já determinado no ovo antes e a partir da 
fecundação. Esses estudos morfológicos, especialmente o descobrimento dos cromossomos acessórios e sexua is, junto à hipótese relativa ao dimorfismo dos gametas e sua relação com a determinação do sexo, ta mbém fizeram surg ir entre os embriolog ista s a disc ussã o acerca do momento em que se produzia a determinação ou fixação do caráter do sexo e determinaram interesses confluentes entre citologia e morfologia. A autora mostra como a embriologia experimental é a plicada à questão da determinação do sexo e como esses estudos experimenta is confluíram.

No capítulo 10, apresenta a participação espanhola na biologia do sexo e demonstra que mesmo se considerados os conhecimentos tardios nesse país, as contribuições espanholas se sucederam rapidamente desde o primeiro terço do século $X X$, ainda se consideradas as conseqüências da sua intemupção de 1936 a 1939 por causa da guerra. Sua análise das public ações espanholas, como o fez em relação a outros países, permitiu à autora situar o contexto institucional, as bibliog rafias dos autores, a formação acadêmica dos profissionais, suas relações com diferentes campos do conhecimento, bem como destacar as influências das diferentes escolas de investigação.

Para concluir, é preciso dizer que se trata de um trabalho de riqueza incomensurável, especialmente, no seu aspecto metodológic o e no modo como o material documental é tratado, vindo a se constituir, nesse sentido, em um bom exemplar de aprendizagem acadêmica para quem deseja trabalhar com fontes semelhantes. Mas, além disso, é original e fundamental para refletir sobre as teorias da determinação do sexo e sua s contribuições para o campo dos estudos em gênero e ciência.

Notas

${ }^{1}$ OUDSHOORN, 1990, 1993, 1998 e 2000; e Nelly OUDSHO ORN e Marta KIREJ CZYK, 2000.

${ }^{2}$ KRAUS, 2000

${ }^{3}$ TAMANINI, 2006.

${ }^{4}$ LOWY e GARDEY, 2000.

\section{Referências bibliográficas}

KRAUS, Cynthia. "La bicatégoriza ção par sexe à l'epreuve de la science. Les cas des recherches en biologie sur la détermination du sexe chez les Humans". In: LOWY, llana; GARDEY, Delphine (Eds.). L'Invention du naturel, les sciences et la fabrication du féminin et du masc ulin. Paris: Éditions des Arc hives Contemporaines, 2000. p. 187-227.

LOWY, llana; GARDEY, Delphine (Eds.). L'Invention de naturel, les sciences et la fabrication du féminin et du masculin. Paris: Editions des Archives Contemporâneos, 2000.

OUDSHOORN, Nelly. On the Making of Sex Hormones: Research Materials and the Production of Knowledge. Social Studies of Science, London, Newbury Park and New Delhi: Sage Periodical Press, v. 20, 1990. p. 533.

"United We Stand: The Pharmaceutical Industry, Laboratory, and Clinic in the Development of Sex Hormones Into Scientific Drugs, 1920-1940." Science Techonology \& Human Values, London: Sage Periodical Press, v. 18, n. 1, 1993. p. 5-23.

. "Hormones, technique et corps: l'archeologie des hormones sexuelles (1923-1940)". Annales HSS, n. 4-5, p. 775-793, 1998.

"Au sujet des corps, des technique et des feminismes". In: GARDEY, Delphine; LOWY, llana (Eds.). Linvention du naturel, les sciences et la fabrication du feminine et du masculine. Paris: Éditions des Archives Contemporaines, 2000. p. 31- 44.

OUDSHO ORN, Nelly, and KIREJ CZYK, Marta. Bodies of Techonology: Women's Involvement with Reproductive Medic ine. Georgia: Ohio State University, 2000. p. 278-303.

TAMANINI, Marlene. "¿Tecnología de óvulos y espermatozoides para sexaje de embriones?" In: CARVALHO, Marília G. de; TAMANINI, Marlene. Diversidad cultural, género y tecnología: un abordage interdisciplinario. Curitiba: Editora UTFPR, 2006. p. 121-158.

Marlene Tamanin Universidade Federal do Paraná 